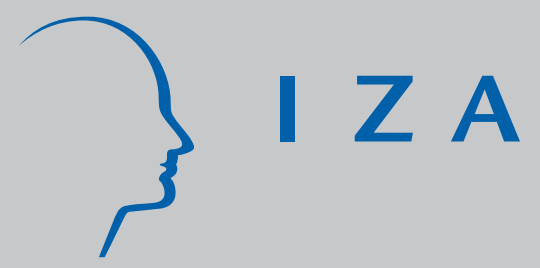

IZA DP No. 230

Should I Stay or Should I Go?

Educational Choices and Earnings:

An Empirical Study for Portugal

Leonor Modesto

December 2000 


\title{
Should I Stay or Should I Go? Educational Choices and Earnings: An Empirical Study for Portugal
}

\author{
Leonor Modesto \\ FCEE, Universidade Católica Portuguesa and IZA, Bonn
}

Discussion Paper No. 230
December 2000

\author{
IZA \\ P.O. Box 7240 \\ D-53072 Bonn \\ Germany \\ Tel.: +49-228-3894-0 \\ Fax: +49-228-3894-210 \\ Email: iza@iza.org
}

This Discussion Paper is issued within the framework of IZA's research of area The Future of Work. Any opinions expressed here are those of the author(s) and not those of the institute. Research disseminated by IZA may include views on policy, but the institute itself takes no institutional policy positions.

The Institute for the Study of Labor (IZA) in Bonn is a local and virtual international research center and a place of communication between science, politics and business. IZA is an independent, nonprofit limited liability company (Gesellschaft mit beschränkter Haftung) supported by the Deutsche Post AG. The center is associated with the University of Bonn and offers a stimulating research environment through its research networks, research support, and visitors and doctoral programs. IZA engages in (i) original and internationally competitive research in all fields of labor economics, (ii) development of policy concepts, and (iii) dissemination of research results and concepts to the interested public. The current research program deals with (1) mobility and flexibility of labor markets, (2) internationalization of labor markets and European integration, (3) the welfare state and labor markets, (4) labor markets in transition, (5) the future of work, (6) project evaluation and (7) general labor economics.

IZA Discussion Papers often represent preliminary work and are circulated to encourage discussion. Citation of such a paper should account for its provisional character. 
IZA Discussion Paper No. 230

December 2000

\title{
ABSTRACT \\ Should I Stay or Should I Go? Educational Choices and Earnings: An Empirical Study for Portugal
}

\begin{abstract}
In this paper we analyse educational choices and earnings of individuals at two different levels in the Portuguese educational system. At each potential exit level we consider two decisions: the decision to continue studying and the employment decision, whereas normally only the first decision is modelled. Correlation between the error terms of the earnings functions and the decision functions, for each level of education, is allowed and we correct for the potential selectivity bias.

We find empirical support for the existence of selectivity bias as the errors of the earnings functions are correlated with the disturbances of both decision functions for both educational levels considered. Moreover it is precisely the existence of selectivity mechanisms that renders the decisions actually taken by individuals optimal in terms of comparative earnings advantage. The obtained marginal rates of return to additional education vary between 2.3 and 9.6 percent per additional year of schooling, depending on whether or not selectivity effects are excluded from the computations. This finding reinforces again the importance of selectivity mechanisms in explaining educational choices.
\end{abstract}

JEL Classification: $\quad$ I20, J31

Keywords: Educational choices, earnings, selectivity

Leonor Modesto

Universidade Católica Portuguesa

FCEE

Palma de Cima

1649-023 Lisboa

Portugal

Tel.: + $351-217214242$

Fax : +351-21 7270252

Email: Irm.fcee.ucp.pt 


\section{Introduction}

Educational choices are now seen as an investment decision following the human capital theory, that assumes that decisions on the length of education are taken comparing expected future returns to its opportunity cost. Also selectivity is now recognized as an important aspect when analysing schooling decisions and measuring the returns to educational choices. Indeed the observed choice is not exogenous, but on the contrary is an optimal action, so that the sample of individuals who make each choice is not random. Empirical support for this sample selection bias has been found in many studies. See for example Willis and Rosen (1979). Therefore, it is important to correct for self selection in estimation, and methods for treating this problem are by now well known.

In this paper we analyse the decision to participate in extended education and the employment decision for individuals at two different levels in the Portuguese educational system, and estimate an earnings function for each educational level considered. Correlation between the error terms of the earnings functions and the decision functions, for each level of education, is allowed and we correct for the potential selectivity bias.

The Portuguese educational system allows a wide range of possible school careers. However, until the ninth grade school attendance is compulsory. After having completed compulsory schooling an individual faces the following decision. Either he decides to continue studying or he quits school and joins the labour force. If he decides to quit school he might get a job or not. If he decides to continue studying he can then choose between different school careers. Namely he can choose either to go to a professional school or to stay in the general system. In both cases, after graduation, he has to choose between continuing studying or not. If he stops and joins the labour force he may, as before, obtain a job or not. If he goes on studying, he can choose between university or other higher, more professional oriented, schooling choices.

In this paper we do not study, nor do we have data on individual school careers. We simply model the individual choice to participate in extended education and the employer choice to make or not a job offer. The data we have comes from two surveys, conducted by the Portuguese Ministry of Education, respectively among those individuals that completed compulsory school (9th grade) and those that finished the complete general system of education (12th grade). At each potential exit level we consider two decisions: the decision to continue studying and the job offer decision. Moreover, for each of the two educational levels considered in this study, we distinguish an earnings equation containing individual and job characteristics. We also assume that both the decision to participate in further education and the employer decision whether or not to recruit are made on the basis of individual characteristics and social 
background variables only. Note that this is not a restrictive assumption as it simply implies that expected future earnings differentials, reservation wages and employers perceptions also depend on the social background and personal characteristics of each individual.

\section{The Model}

\subsection{The general case}

After having completed successfully one educational level an individual faces two decisions: his own decision to continue studying or to join the labour force $\left(I_{1}^{*}\right)$ and the employer decision to recruit him or not $\left(I_{2}^{*}\right)$. Earnings are only observed for those individuals that are working. We also assume that these decisions depend on personal characteristics and social background i.e.:

$$
\begin{aligned}
& I_{1}^{*}=\gamma_{1}^{\prime} X_{1}+u_{1} \\
& I_{2}^{*}=\gamma_{2}^{\prime} X_{2}+u_{2}
\end{aligned}
$$

where $u_{j}(j=1,2)$ are stochastic errors and $\gamma_{j}$ are vectors of parameters. $I_{j}^{*}$ are unobserved variables and what we observed are the realized choices. If $I_{1}^{*} \geq 0$, the individual decides to join the labour force. If $I_{2}^{*} \geq 0$ the employer would want to offer him a job. Note that (2) exists and is defined even for those individuals that decided not to join the labour force. Indeed there are persons that do not join the labour force but to whom employers would want to offer jobs.

Let us define the following variables:

$$
\begin{aligned}
& I_{j}=1 ; \quad \text { if } I_{j}^{*} \geq 0 \\
& I_{j}=0 ; \quad \text { if } I_{j}^{*}<0
\end{aligned}
$$

Earnings can only be observed if $I_{1}=1$ and $I_{2}=1$. We assume that earnings for individuals with a certain level of education are given by:

$$
W=\alpha^{\prime} Z+e
$$

where $W$ stands for the log of earnings and the variables in $Z$ reflect both personal and job characteristics.

Estimates of equation (5), for each education level, obtained by conventional linear regression techniques may be inconsistent. This inconsistency occurs, due to the existence of the two selections discussed previously, if the disturbances of the selection equations and the earnings equation are correlated. This problem can be handled using either a two-step method due to Heckman (1979) 
("Heckit") or maximum likelihood estimation. Heckit has been widely used in the presence of one selection rule. However, it can become very cumbersome when there is more than one selection rule. ${ }^{1}$ In this work we obtain consistent estimates by estimating jointly, using maximum likelihood for each educational level, the earnings equation and the two decision functions, eliminating the selection biases. Assuming that the error terms follow a multivariate normal distribution the likelihood function is relatively simple and the obtained estimators are not only consistent, but also are asymptotically efficient and normally distributed.

So we further assume that $\left(e, u_{1}, u_{2}\right) \sim N\left(0, \sum\right)$ with:

$$
\sum=\left[\begin{array}{ccc}
\sigma_{e}^{2} & \sigma_{e u_{1}} & \sigma_{e u_{2}} \\
\sigma_{e u_{1}} & 1 & 0 \\
\sigma_{e u_{2}} & 0 & 1
\end{array}\right]
$$

Note that for identification purposes the variances of $u_{1}$ and $u_{2}$ are normalized to 1 . Moreover we have assumed that $\sigma_{u_{1} u_{2}}=0$ for simplicity. Indeed, if the two selections are not correlated, both the estimation of the parameters and the computation of the selectivity effects (the so-called lambdas) become much simpler. Also in our case we experienced convergence problems when we did not impose this restriction. Moreover, frequently when this restriction is not imposed, the obtained correlation is not found to be significantly different from zero. See Tunali (1986) and Co, Gang and Yun (2000).

In this case the likelihood function for the entire sample is then given by:

$$
\begin{aligned}
& L=\prod_{i}\left[\Phi\left(-\gamma_{1}^{\prime} X_{1 i}\right)\right]^{1-I_{1 i}}\left[\left[1-\Phi\left(-\gamma_{1}^{\prime} X_{1 i}\right)\right]\left[\Phi\left(-\gamma_{2}^{\prime} X_{2 i}\right)\right]\right]^{I_{1 i}\left(1-I_{2 i}\right)} \\
& {\left[\int_{-\gamma_{1}^{\prime} X_{1 i}}^{\infty} \int_{-\gamma_{2}^{\prime} X_{2 i}}^{\infty} f\left(e, u_{1}, u_{2}\right) d u_{2} d u_{1}\right]^{I_{1 i} I_{2 i}} }
\end{aligned}
$$

As

$$
f\left(e, u_{1}, u_{2}\right)=f(e) f\left(u_{1}, u_{2} \mid e\right)
$$

we have that:

$\int_{-\gamma_{1}^{\prime} X_{1 i}}^{\infty} \int_{-\gamma_{2}^{\prime} X_{2 i}}^{\infty} f\left(e, u_{1}, u_{2}\right) d u_{2} d u_{1}=f(e) \int_{-\gamma_{1}^{\prime} X_{1 i}}^{\infty} \int_{-\gamma_{2}^{\prime} X_{2 i}}^{\infty} f\left(u_{1}, u_{2} \mid e=W-\alpha^{\prime} Z\right) d u_{2} d u_{1}$

where:

$$
f(e)=\frac{1}{\sigma_{e}} \phi\left(\frac{W-\alpha^{\prime} Z}{\sigma_{e}}\right)
$$

\footnotetext{
${ }^{1}$ See Tunali (1986) and Fishe et al. (1981).
} 
and

$$
f\left(u_{1}, u_{2} \mid e\right) \sim N\left(\left[\begin{array}{c}
\frac{\rho_{e u_{1}}}{\sigma_{e}} e \\
\frac{\rho_{e u_{2}}}{\sigma_{e}} e
\end{array}\right],\left[\begin{array}{cc}
1-\rho_{e u_{1}}^{2} & -\rho_{e u_{1}} \rho_{e u_{2}} \\
-\rho_{e u_{1}} \rho_{e u_{2}} & 1-\rho_{e u_{2}}^{2}
\end{array}\right]\right)
$$

where $\sigma_{e u_{i}}=\rho_{e u i} \sigma_{e}$.

This implies that :

$$
\begin{gathered}
\int_{-\gamma_{1}^{\prime} X_{1 i}}^{\infty} \int_{-\gamma_{2}^{\prime} X_{2 i}}^{\infty} f\left(e, u_{1}, u_{2}\right) d u_{2} d u_{1}=\left[\frac{1}{\sigma_{e}} \phi\left(\frac{W-\alpha^{\prime} Z}{\sigma_{e}}\right)\right]\left\{1-\Phi\left[\frac{-\gamma_{1} X_{1 i}-\frac{\rho_{e u_{1}}}{\sigma_{e}}\left(W_{i}-\alpha^{\prime} Z_{i}\right)}{\sqrt{1-\rho_{e u_{1}}^{2}}}\right]\right. \\
-\Phi\left[\frac{-\gamma_{2}^{\prime} X_{2 i}-\frac{\rho_{e u_{2}}}{\sigma_{e}}\left(W_{i}-\alpha^{\prime} Z_{i}\right)}{\sqrt{1-\rho_{e u_{2}}^{2}}}\right] \\
\left.+C D F\left(\frac{-\gamma_{1} X_{1 i}-\frac{\rho_{e u_{1}}}{\sigma_{e}}\left(W_{i}-\alpha^{\prime} Z_{i}\right)}{\sqrt{1-\rho_{e u_{1}}^{2}}}, \frac{-\gamma_{2}^{\prime} X_{2 i}-\frac{\rho_{e u_{2}}}{\sigma_{e}}\left(W_{i}-\alpha^{\prime} Z_{i}\right)}{\sqrt{1-\rho_{e u_{2}}^{2}}}, \rho\right)\right\}
\end{gathered}
$$

where $\phi, \Phi$ are the standard normal univariate density and CDF respectively and where $\rho=-\rho_{e u_{1}} \rho_{e u_{2}} /\left(\sqrt{1-\rho_{e u_{1}}^{2}} \sqrt{1-\rho_{e u_{2}}^{2}}\right)$.

The previous derivations assumed that earnings where observed for those individuals that had a job. However, unfortunately, the data set that we have is such that, for those individuals that are working, we don't observe their actual level of earnings. Instead we are only informed whether the earnings of an individual which is working fall on a certain range. We could allow for this feature of the data set defining a set of dummy variables $W I_{j}$, one for each earnings class $j$ such that:

$$
W I_{j i}=1 \quad \text { if } \quad a_{j-1} \leq W_{i}<a_{j}
$$

where the $a_{j}$ are known constants and $a_{0}=-\infty$ and $a_{9}=\infty$. This means that:

$$
\begin{gathered}
\operatorname{Prob}\left(W I_{j i}=1 ; I_{1 i}=1 ; I_{2 i}=1\right)=\operatorname{Prob}\left(a_{j-1} \leq W_{i}<a_{j} ; I_{1 i}^{*}>0 ; I_{2 i}^{*}>0\right) \\
=\operatorname{Prob}\left(a_{j-1}-\alpha^{\prime} Z_{i} \leq e<a_{j}-\alpha^{\prime} Z_{i} ; u_{1}>-\gamma_{1}^{\prime} X_{1 i} ; u_{2}>-\gamma_{2}^{\prime} X_{2 i}\right)
\end{gathered}
$$

so that:

$\operatorname{Prob}\left(W I_{j i}=1 ; I_{1 i}=1 ; I_{2 i}=1\right)=\int_{-\gamma_{1}^{\prime} X_{1 i}}^{\infty} \int_{-\gamma_{2}^{\prime} X_{2 i}}^{\infty} \int_{a_{j-1}-\alpha^{\prime} Z_{i}}^{a_{j}-\alpha^{\prime} Z_{i}} f\left(e, u_{1}, u_{2}\right) d e d u_{2} d u_{1}$

In this case the likelihood function becomes: 


$$
\begin{aligned}
L & =\prod_{i}\left\{\left[\Phi\left(-\gamma_{1}^{\prime} X_{1 i}\right)\right]^{1-I_{1 i}}\left[\left[1-\Phi\left(-\gamma_{1}^{\prime} X_{1 i}\right)\right]\left[\Phi\left(-\gamma_{2}^{\prime} X_{2 i}\right)\right]\right]^{I_{1 i}\left(1-I_{2 i}\right)}\right. \\
& \left.\prod_{j}\left[\int_{-\gamma_{1}^{\prime} X_{1 i}}^{\infty} \int_{-\gamma_{2}^{\prime} X_{2 i}}^{\infty} \int_{a_{j-1}-\alpha^{\prime} Z_{i}}^{a_{j}-\alpha^{\prime} Z_{i}} f\left(e, u_{1}, u_{2}\right) d e d u_{2} d u_{1}\right]^{W_{j i} I_{1 i} I_{2 i}}\right\}
\end{aligned}
$$

However, due to the computational burden involved instead of maximising (10) we chose to simply maximize (7) approximating the actual earnings of each individual by the mid-point of the corresponding earnings class interval.

Our model can be compared with several other models that have also analysed educational choices and earnings. For example in Trost and Lee (1984), Garen (1984) and Hartog et al. (1989) the same problem is analysed using similar data. However in the models of Trost and Lee and Garen the exit level is chosen at the start of the school career. Therefore, implicitly they assume complete information at the beginning of the school career. On the contrary Hartog et al. consider a sequential decision process for the choice of schooling level. In their model, like in ours, at each education level an individual must decide to stay in school or to stop studying. Furthermore they also assume, as we do, that choices made at one educational level do not depend on decisions taken previously. This is a strong assumption, due both to the computational burden associated with the alternative and, in our case, also by data availability. Note that in the Trost and Lee case, as they consider a multinomial choice logit, they also impose independence between the decision equations. However, in all these works it is assumed that if one individual decides to leave school he or she will get a job. In our model, on the contrary, we relax this assumption, so that an individual that decides to leave school may get a job or not. Therefore, in our case, at each potential exit level we consider two decisions: the decision to leave school and the employment decision, whereas in the other three works only the first decision is modelled.

\subsection{Assuming independence between the decision to study and the earnings function}

If the errors of the earnings function and of the decision to continue studying are uncorrelated, i.e. if $\rho_{e u_{1}}=0$, the model becomes much simpler. Indeed in this case, as we have that $f\left(e, u_{1}, u_{2}\right)=f\left(u_{1}\right) f\left(e, u_{2}\right)$, we can split the model in two parts, and analyse the decision to continue studying or to join the labour force separately.

This means that we can consider two likelihood functions. One for the decision to study $\left(L_{1}\right)$ and another for the remaining aspects $\left(L_{2}\right)$. In this case $L_{1}$ is given by (11): 


$$
L_{1}=\prod_{i}\left[1-\Phi\left(-\gamma_{1}^{\prime} X_{1 i}\right)\right]^{I_{1 i}}\left[\Phi\left(-\gamma_{1}^{\prime} X_{1 i}\right)\right]^{1-I_{1 i}}
$$

and we could write $L_{2}$ if actual earnings were observed as:

$$
L_{2}=\prod_{i}\left[\Phi\left(-\gamma_{2}^{\prime} X_{2 i}\right)\right]^{1-I_{2 i}}\left[\int_{-\gamma_{2}^{\prime} X_{2 i}}^{\infty} f\left(e, u_{2}\right) d u_{2}\right]^{I_{2 i}} .
$$

As we have that:

$$
f\left(e, u_{2}\right)=f(e) f\left(u_{2} \mid e\right)
$$

(12) becomes:

$$
L_{2}=\prod_{i}\left[\Phi\left(-\gamma_{2}^{\prime} X_{2 i}\right)\right]^{1-I_{2 i}}\left[f(e) \int_{-\gamma_{2}^{\prime} X_{2 i}}^{\infty} f\left(u_{2} \mid e=W-\alpha^{\prime} Z\right) d u_{2}\right]^{I_{2 i}}
$$

so that:

$$
L_{2}=\prod_{i}\left[\Phi\left(-\gamma_{2}^{\prime} X_{2 i}\right)\right]^{1-I_{2 i}}\left[\frac{1}{\sigma_{e}} \phi\left(\frac{W_{i}-\alpha^{\prime} Z_{i}}{\sigma_{e}}\right) \Phi\left[\frac{\gamma_{2}^{\prime} X_{2 i}+\frac{\rho_{e u_{2}}}{\sigma_{e}}\left(W_{i}-\alpha^{\prime} Z_{i}\right)}{\sqrt{1-\rho_{e u_{2}}^{2}}}\right]\right]_{(13)}^{I_{2 i}}
$$

This means that the likelihood function for the entire sample, if actual earnings were observed, is in this case given by :

$L=\prod_{i}\left[\Phi\left(-\gamma_{1}^{\prime} X_{1 i}\right)\right]^{1-I_{1 i}}\left\{\left[1-\Phi\left(-\gamma_{1}^{\prime} X_{1 i}\right)\right]\left[\Phi\left(-\gamma_{2}^{\prime} X_{2 i}\right)\right]^{1-I_{2 i}}\left[\int_{-\gamma_{2}^{\prime} X_{2 i}}^{\infty} f\left(e, u_{2}\right) d u_{2}\right]^{I_{2 i}}\right\}^{I_{1 i}}$

As we only know whether earnings fall on a certain range the relevant $L_{2}$ likelihood function is in this case given by (15):

$$
L_{2}=\prod_{i}\left\{\left[\Phi\left(-\gamma_{2}^{\prime} X_{2 i}\right)\right]^{1-I_{2 i}} \prod_{j}\left[\int_{-\gamma_{2}^{\prime} X_{2 i}}^{\infty} \int_{a_{j-1}-\alpha^{\prime} Z_{i}}^{a_{j}-\alpha^{\prime} Z_{i}} f\left(e, u_{2}\right) d e d u_{2}\right]^{I_{2 i} W_{j i}}\right\}
$$

where:

$$
\begin{gathered}
\int_{-\gamma_{2}^{\prime} X_{2 i}}^{\infty} \int_{a_{j-1}-\alpha^{\prime} Z_{i}}^{a_{j}-\alpha^{\prime} Z_{i}} f\left(e, u_{2}\right) d e d u_{2}=\Phi\left[\frac{a_{j}-\alpha^{\prime} Z_{i}}{\sigma_{e}}\right]-\Phi\left[\frac{a_{j-1}-\alpha^{\prime} Z_{i}}{\sigma_{e}}\right] \\
-C D F\left(\frac{a_{j}-\alpha^{\prime} Z_{i}}{\sigma_{e}},-\gamma_{2}^{\prime} X_{2 i}\right)+C D F\left(\frac{a_{j-1}-\alpha^{\prime} Z_{i}}{\sigma_{e}},-\gamma_{2}^{\prime} X_{2 i}\right) .
\end{gathered}
$$


Therefore the likelihood function for the entire sample becomes in this case:

$$
\begin{aligned}
& L=\prod_{i}\left\{\left[\Phi\left(-\gamma_{1}^{\prime} X_{1 i}\right)\right]^{1-I_{1 i}}\left[1-\Phi\left(-\gamma_{1}^{\prime} X_{1 i}\right)\right]^{I_{1 i}}\left[\Phi\left(-\gamma_{2}^{\prime} X_{2 i}\right)\right]^{\left(1-I_{2 i}\right) I_{1 i}}\right. \\
&\left.\prod_{j}\left[\int_{-\gamma_{2}^{\prime} X_{2 i}}^{\infty} \int_{a_{j-1}-\alpha^{\prime} Z_{i}}^{a_{j}-\alpha^{\prime} Z_{i}} f\left(e, u_{2}\right) d e d u_{2}\right]^{W_{j i} I_{1 i} I_{2 i}}\right\} .
\end{aligned}
$$

\section{The Data}

The data set used in this study comes from two surveys, conducted by the Portuguese Ministry of Education, respectively among those individuals that completed compulsory school (9th grade) and those that finished the complete general system of education (12th grade) in 1993. These individuals were interviewed, at the same calendar time, in December 1994, 18 months after graduation, and were asked about some personal characteristics and family background, as well as their current situation at the time of the interview: i.e. whether they were studying, working or out of work. For those that were employed some questions concerning their current job and earnings were also asked. Note that for those individuals that continued studying we do not know what was their schooling type choice.

The explanatory variables considered in the decision to continue studying (i.e. the variables in the $X_{1}$ vector) include personal characteristics: SEX (a dummy variable equal to 1 for women), AGE measured at the time of the interview, and also social background variables: the profession of both father and mother (JOBPA and JOBMA), schooling level of both parents (SCPA and SCMA) as well as the current labour market situation of both parents at the time of the interview (SITPA and SITMA).

The variables JOBPA and JOBMA are dummy variables that take the value zero for lower and intermediate level jobs and the value one for higher level jobs. Note that in estimation we only used the JOBPA variable as both JOB variables moved together. The variables SCPA and SCMA are a set of seven dummy variables for each parent. For example SCPA1 takes the value 1 when the father has less than primary school (4 years in school). The other educational levels considered are: primary school (SCPA2 and SCMA2), 6th grade (SCAPA3 and SCMA3), 9th grade (SCPA4 and SCMA4), 12th grade (SCPA5 and SCMA5), higher education (SCPA6 and SCMA6) and college education (SCPA7 and SCMA7). The variables SITPA and SITMA are also dummy variables that indicate whether mother and father were employed (SITPA1 and SITMA1), unemployed (SITPA2 and SITMA2), house-working (SITPA3 and SITMA3), retired or pensionists (SITPA4 and SITMA4) or deceased (SITPA5 
and SITMA5) at the time of the interview. In the estimation the variables SCPA1, SCMA1, SITPA5 and SITMA5 were omitted and serve therefore as the reference category.

The exogenous variables used in the employment decision (i.e. the variables in the $X_{2}$ vector) are the ones in $X_{1}$ plus GRAD, a variable concerning the grade obtained at school graduation, that is supposed to reflect the individual's general ability. GRAD is also a dummy variable that takes the value 1 when the grade obtained exceeds $66 \%$.

Finally the explanatory variables included in the wage equations (i.e. the variables in the $Z$ vector) are the ones in $X_{2}$ plus a variable intended to characterize the firm at which the individual is working (SIZE), others that reflect the type of working relationship (CONT and PARTT) and another that assesses the job level and skills of the individual (QUAL). The variable size of the firm (measured by the number of employees) was included in the wage equations, as it has been found that large employers pay higher wages. (See Brown and Medoff (1989)). We considered 6 size classes and therefore defined 6 dummy variables: less than 5 workers (SIZE1), more than 5 and less than 20 workers (SIZE2), 20 or more and less than 50 workers (SIZE3), 50 or more and less than 100 workers (SIZE4), 100 or more and less than 500 workers (SIZE5), and more than 500 employees (SIZE6). In estimation SIZE1 was omitted. The variable CONT is a dummy variable that takes the value 1 when the individual is employed with a permanent labour contract. PARTT is a dummy variable for people working part time. Finally QUAL indicates what was the level of qualification of the individual. Again we considered a set of dummy variables, one for each qualification level. Note that in our data each respondent selected its own qualification level from a given list of choices and that the list was not identical for the two educational levels considered.

The inclusion of the qualification level variables and of the size variables in the earnings function may need some more discussion, as it not usually done. The standard human capital model ignores job level and firm size variables, assuming either that the value of human capital is independent of job level and size of the firm or that individuals always find the job level or the firm size that gives them the proper returns. However, other theories, such as job-worker matching theories, suggest that demand side variables may also play a relevant role. Moreover previous empirical work shows that both job level and firm size are important variables in the determination of wages. See Hartog et al. (1989) and Brown and Medoff (1989). Also the inclusion of the size variables may be justified in terms of the human capital theory if we consider that individuals prefer to work in small firms, so that they have to be compensated to agree to work in a bigger firm. Indeed, undesirable working conditions, generally associated with bigger firms, such as more rules and or a less friendly and more impersonal working atmosphere may imply the need for a wage premium associated with employer size.

The endogenous variables, at each potential exit level, are the dummy vari- 
ables $I_{1}$ and $I_{2}$ and respectively the monthly wage (in logs) or the dummy variables $W I_{j}$ defined in (8). Note that the constants $a_{j}$, that define the limits of the earnings intervals, are not identical for the two educational levels considered.

In Table 1 we present means and standard deviations of all the exogenous variables by educational level. As expected mean age is higher for the sample of individuals that completed the 12th grade and we also observe a higher proportion of females in the 12th grade sample. Looking now at family background effects, although the proportion of individuals whose father had a high level job or whose parents schooling level was at least the 12th grade are higher for the higher educational level, we do not detect a sharp difference between the two educational levels considered. This may be explained by the fact that the statistics presented are computed for the complete sample of individuals at each educational level and not for those exiting the educational system at that level, and that for the 9th grade sample the proportion of individuals that stopped studying is relatively small. These considerations, however, do not apply to the labour market variables, and for those we can detect some important differences. Indeed the proportion of individuals employed by bigger firms (SIZE5 and SIZE6) or with a permanent labour contract are significantly higher for individuals that hold a 12 th grade certificate. Another interesting fact, probably also related to the age difference between the two samples, is that the proportion of individuals whose parents are employed (SITPA1 and SITMA1) is much smaller for the 12th grade sample whereas the proportion of individuals whose parents are retired or pensionists (SITPA4 and STMA4) increases compensatorily.

In Table 2 we present means and standard deviations of the wage variables by educational level. As expected mean wages are bigger in the 12 th grade sample. Note again that the limits of the earnings intervals are not the same for the two educational levels.

\section{Empirical Results}

\subsection{The case with $\rho_{e u_{1}}=0$}

We start by presenting the results obtained for the case where $\rho_{e u_{1}}=0$. Note that in this case, contrary to what we did for the general case, we fully accounted for the fact that in our data actual earnings are not observed, although we know inside what interval do individual earnings fall. This means that the two cases actually estimated are not nested.

When $\rho_{e u_{1}}=0$ we can treat the decision to continue studying separately. Therefore to ease the computational burden we decided in this case instead of maximising (17) to split the model in two parts and to maximise (11) and (15) separately for each educational level. 


\begin{tabular}{|l|ll|ll|}
\hline Variable & 9th grade & & 12th grade & \\
\hline X1 Variables & Mean & Std. dev. & Mean & Std. dev. \\
SEX & 0.6062 & 0.4887 & 0.6419 & 0.4797 \\
AGE & 16.804 & 1.4153 & 21.350 & 3.9783 \\
JOBPA & 0.1972 & 0.3980 & 0.2274 & 0.4193 \\
SCPA2 & 0.5111 & 0.5000 & 0.5050 & 0.5002 \\
SCPA3 & 0.0885 & 0.2841 & 0.0744 & 0.2626 \\
SCPA4 & 0.1562 & 0.3632 & 0.1439 & 0.3511 \\
SCPA5 & 0.0566 & 0.2312 & 0.0704 & 0.2560 \\
SCPA6 & 0.0359 & 0.1861 & 0.0473 & 0.2124 \\
SCPA7 & 0.0794 & 0.2704 & 0.0885 & 0.2842 \\
SCMA2 & 0.5212 & 0.4997 & 0.5201 & 0.4999 \\
SCMA3 & 0.1001 & 0.3002 & 0.0724 & 0.2593 \\
SCMA4 & 0.1269 & 0.3329 & 0.1087 & 0.3114 \\
SCMA5 & 0.0521 & 0.2222 & 0.0453 & 0.2080 \\
SCMA6 & 0.0546 & 0.2273 & 0.0634 & 0.2438 \\
SCMA7 & 0.0571 & 0.2322 & 0.0624 & 0.2420 \\
SITPA1 & 0.8124 & 0.3905 & 0.6801 & 0.4667 \\
SITPA23 & 0.0490 & 0.2160 & 0.0553 & 0.2287 \\
SITPA4 & 0.0748 & 0.2632 & 0.1650 & 0.3714 \\
SITMA1 & 0.5420 & 0.4984 & 0.4759 & 0.4997 \\
SITMA2 & 0.0460 & 0.2096 & 0.0372 & 0.1894 \\
SITMA3 & 0.3296 & 0.4702 & 0.3441 & 0.4753 \\
SITMA4 & 0.0445 & 0.2062 & 0.0956 & 0.2942 \\
Number of Observ. & 1978 & & 994 & \\
\hline X2 Variables & & & & \\
GRAD & 0.3352 & 0.4734 & 0.2767 & 0.4479 \\
Number of Observ. & 176 & & 430 & \\
\hline Z Variables & & & & \\
SIZE2 & 0.1919 & 0.3958 & 0.1899 & 0.3230 \\
SIZE3 & 0.1616 & 0.3700 & 0.1434 & 0.3511 \\
SIZE4 & 0.1010 & 0.3029 & 0.0968 & 0.2962 \\
SIZE5 & 0.0808 & 0.2739 & 0.1470 & 0.3547 \\
SIZE6 & 0.1616 & 0.3700 & 0.2186 & 0.4141 \\
CONT & 0.2121 & 0.4109 & 0.3871 & 0.4880 \\
PARTT & 0.1313 & 0.3395 & 0.1111 & 0.3148 \\
QUAL1 & 0.0808 & 0.2739 & 0.1075 & 0.3103 \\
QUAL2 & 0.5152 & 0.5023 & 0.0538 & 0.2260 \\
Number of Observ. & 99 & & 279 & \\
\hline & & & & \\
\hline
\end{tabular}

Table 1: Means and Standard Deviations of Variables 


\begin{tabular}{|l|ll|ll|}
\hline Variable & 9th grade & & 12th grade \\
\hline & Mean & Std. dev. & Mean & Std. dev. \\
log wage & 4.0125 & 0.3276 & 4.3166 & 0.3854 \\
$W I_{1}$ & 0.0808 & 0.2739 & 0.0609 & 0.2396 \\
$W I_{2}$ & 0.0505 & 0.2201 & 0.0896 & 0.2861 \\
$W I_{3}$ & 0.0909 & 0.2889 & 0.1864 & 0.3901 \\
$W I_{4}$ & 0.1919 & 0.3958 & 0.2186 & 0.4141 \\
$W I_{5}$ & 0.2424 & 0.4307 & 0.1541 & 0.3617 \\
$W I_{6}$ & 0.2323 & 0.4245 & 0.1470 & 0.3547 \\
$W I_{7}$ & 0.0707 & 0.2576 & 0.0538 & 0.2260 \\
$W I_{8}$ & 0.0303 & 0.1723 & 0.0645 & 0.2461 \\
$W I_{9}$ & 0.0101 & 0.1005 & 0.0251 & 0.1567 \\
$\mathrm{~N}$ & 99 & & 279 & \\
\hline
\end{tabular}

Table 2: Means and Standard Deviations of the Wage Variables

The results obtained maximizing (11) are presented in Table 3. In column (i) we present the results obtained for the 9th grade whereas in columns (ii) and (iii) we present two alternative specifications for the 12th grade. The first one (column (ii)) is identical to the one presented for the 9th grade. As with that specification many variables had no significant effect we decided to change the specification, mainly by deleting the SCPA and SITPA variables, and arrived at the specification presented in column (iii) which is our preferred specification for the 12th grade.

Looking at the parameters estimates we can see that sex only influences significantly the decision to continue studying at the 9 th grade where we find that girls tend to go on studying more than boys. Also age tends to increase the probability to exit school at both educational levels. Turning now to the family background effects we find, for both educational levels, that the variable JOBPA shows the expected sign, as individuals whose father has a high level job tend to continue studying, although the obtained effect is not significantly estimated. Moreover, for the 9 th grade, having a more educated father increases the probability of continuing studying and for both educational levels the probability of exiting school is lower the higher the mother's education. Also, for the 9th grade, individuals whose father is employed have a higher probability of continuing in school and this probability is even higher if the father is retired. For both educational levels we find that individual whose mother is unemployed have a higher probability of exiting school.

In Table 4 the results of the maximization of $L_{2}$ are presented. There are three parts: the parameter estimates of the decision function $I_{2}^{*}$, the parameter estimates of the earnings function and the parameters of the covariance matrix. (Asymptotic t-ratios are presented in parentheses). In the last two columns we present the results obtained maximizing equation (15) respectively for the 


\begin{tabular}{|l|ll|ll|ll|}
\hline & (i) & & (ii) & & (iii) & \\
\hline & 9th grade & & 12th grade & & 12th grade & \\
\hline Variable & Param. & t-ratio & Param. & t-ratio & Param. & t-ratio \\
constant & -5.919 & $(-10.15)$ & -3.446 & $(-6.98)$ & -3.565 & $(-7.84)$ \\
SEX & -0.481 & $(-5.08)$ & -0.130 & $(-1.34)$ & -0.120 & $(-1.25)$ \\
AGE & 0.316 & $(11.46)$ & 0.172 & $(9.96)$ & 0.176 & $(10.42)$ \\
JOBPA & -0.259 & $(-1.69)$ & -0.190 & $(-1.60)$ & -0.170 & $(-1.46)$ \\
SCPA23 & -0.110 & $(-0.69)$ & -0.010 & $(-0.05)$ & & \\
SCPA4 & -0.234 & $(-1.12)$ & -0.408 & $(-1.77)$ & & \\
SCPA567 & -0.769 & $(-2.33)$ & -0.080 & $(-0.33)$ & & \\
SCMA2 & & & & & -0.169 & $(-1.17)$ \\
SCMA3 & & & & & -0.566 & $(-2.66)$ \\
SCMA23 & -0.358 & $(-2.55)$ & -0.169 & $(-1.12)$ & & \\
SCMA4 & -0.818 & $(-3.47)$ & -0.643 & $(-2.91)$ & -0.818 & $(-4.13)$ \\
SCMA5 & & & & & -1.020 & $(-3.66)$ \\
SCMA6 & & & & & -1.165 & $(-4.32)$ \\
SCMA7 & & & & & -1.218 & $(-4.23)$ \\
SCMA567 & -1.356 & $(-3.66)$ & -1.018 & $(-4.22)$ & & \\
SITPA1 & -0.614 & $(-3.51)$ & 0.030 & $(0.18)$ & & \\
SITPA23 & -0.407 & $(-1.66)$ & 0.069 & $(0.28)$ & & \\
SITPA4 & -0.865 & $(-3.75)$ & 0.087 & $(0.45)$ & & \\
SITMA1 & 0.614 & $(2.35)$ & -0.007 & $(-0.03)$ & 0.059 & $(0.27)$ \\
SITMA2 & 0.874 & $(2.79)$ & 0.522 & $(1.72)$ & 0.610 & $(2.05)$ \\
SITMA3 & 0.528 & $(2.02)$ & 0.190 & $(0.85)$ & 0.227 & $(1.06)$ \\
SITMA4 & 0.325 & $(1.00)$ & 0.420 & $(1.63)$ & 0.486 & $(1.94)$ \\
\hline R squared & 0.207 & & 0.313 & & 0.313 & \\
correct pred. & 0.914 & & 0.759 & & 0.758 & \\
No. of 1 & 176 & & 430 & & 430 & \\
No. of observ. & 1978 & & 994 & & 994 & \\
\hline
\end{tabular}

Table 3: Probit Estimation Results 


\begin{tabular}{|l|l|l|l|}
\hline & 9th grade & 9th grade & 12th grade \\
\hline & eq. (13) & eq. (15) & eq. (15) \\
\hline Decision function & & & \\
const & $-0.987(-0.80)$ & $-1.015(-0.82)$ & $-1.811(-4.33)$ \\
SEX & $-0.089(-0.44)$ & $-0.091(-0.45)$ & $-0.125(-0.87)$ \\
AGE & $0.054(0.80)$ & $0.056(0.82)$ & $0.103(5.75)$ \\
SCPA4567 & $0.208(0.66)$ & $0.209(0.66)$ & $-0.073(-0.45)$ \\
SITPA4 & $0.879(2.19)$ & $0.881(2.19)$ & $-0.282(-1.82)$ \\
GRAD & $0.250(1.13)$ & $0.248(1.12)$ & $0.071(0.47)$ \\
\hline Earnings function & & & \\
const & $3.170(9.13)$ & $3.174(9.35)$ & $3.646(18.22)$ \\
SEX & - & - & $-0.175(-4.16)$ \\
AGE & $0.029(2.38)$ & $0.029(2.50)$ & $0.019(3.19)$ \\
QUAL1 & $0.213(2.35)$ & $0.212(2.45)$ & $0.024(0.41)$ \\
QUAL2 & $0.075(1.21)$ & $0.071(1.16)$ & $0.106(1.43)$ \\
CONT & $0.143(1.76)$ & $0.146(1.89)$ & $0.127(3.03)$ \\
SIZE2 & $0.185(2.37)$ & $0.171(2.24)$ & $0.082(1.21)$ \\
SIZE3 & $0.054(0.52)$ & $0.044(0.42)$ & $0.151(2.20)$ \\
SIZE4 & $0.305(3.81)$ & $0.278(3.57)$ & $0.202(2.50)$ \\
SIZE5 & $0.388(3.37)$ & $0.383(3.55)$ & $0.275(4.04)$ \\
SIZE6 & $0.240(2.38)$ & $0.230(2.35)$ & $0.369(5.62)$ \\
PARTT & $-0.118(-1.62)$ & $-0.117(-1.64)$ & $-0.233(-3.75)$ \\
GRAD & $0.108(1.79)$ & $0.106(1.75)$ & $0.037(0.81)$ \\
\hline Covariance matrix & \multicolumn{3}{|l}{} \\
$\sigma_{e}$ & $0.241(1.10)$ & $0.226(6.90)$ & $0.323(9.50)$ \\
$\rho_{\text {eu }}$ & $0.266(8.15)$ & $0.233(0.25)$ & $0.520(1.65)$ \\
\hline N & 176 & 176 & 430 \\
Max (log L2) & -112.51 & -275.98 & -776.33 \\
\hline
\end{tabular}

Table 4: Maximum likelihood estimates of $L_{2}$ 
9th and the 12th grades, whereas in the first column we present the results obtained for the 9th grade when we maximize (13) approximating the earnings of an individual by the mid-point of the corresponding earnings class.

It is clear that some of the parameters, mainly those of the decision function, are not significantly estimated. The conclusion that sex and father's level of schooling have no significant effect on the probability of an individual finding a job suggests no discrimination at the choice level. However we find, for the 12 th grade sample, that wages are lower for females. The effect of age on the probability of getting a job is positive but significative only in the 12th grade sample. This may be due to the fact that the variance of the age distribution is much smaller for the 9th grade sample. However age affects significantly and positively earnings at both educational levels. We also find that the grade obtained does not influence neither the probability of becoming employed nor the wage received for the 12th grade sample. This suggests that the grade obtained at graduation does not affect the reservation wage and does not function as a screening device for 12th grade graduates. However, for the 9th grade sample there is some slight evidence of the presence of these effects. These findings suggest that the opportunity cost of working for ablers decreases with the education level. For the 9th grade sample we also find that individuals whose father is retired or a pensionist have a higher probability of becoming employed. However this effect is not present in the 12 th grade sample. We suspect that this may have to do with a certain correlation between this variable and age. For both educational levels, earnings increase with the size of the firm and we also find that there is a wage premium for individuals employed with a permanent labour contract. Also the earnings of individuals working in part-time are smaller as expected.

The bottom part of Table 4 presents information on the variance-covariance structure. We find that the variance in the earnings function increases with the educational level. This is in conformity with other research on earnings. The obtained correlation between the errors of the wage equation and the errors of the employment decision is positive for both educational levels. This indicates that unobserved factors that increase earnings for a given educational level are positively correlated with the unobserved factors that increase the probability of obtaining a job. However, the coefficients obtained are not significantly estimated when we maximize equation (15). Indeed in that case we had some problems in reaching convergence. Note however that when, instead of fully accounting for the fact that actual earnings are not observed, we approximate actual earnings by the mid-point of the corresponding earnings class interval, i. e. when instead of estimating (15) we use (13), we obtain very similar results (compare the first two columns of Table 4) and the correlation coefficient is significantly estimated. This suggests that we can consider that indeed these error terms are positively correlated, which indicates the presence of selectivity mechanisms. Note however that the results presented were obtaining assuming no correlation between the errors of the earnings function and the decision to 
continue studying. Whether this is a plausible assumption remains to be seen.

\subsection{The general case}

When we do not impose that $\rho_{e u_{1}}=0$ the relevant likelihood function is given by (10). However, due to the computational burden involved, and in the light of the results presented previously, we decided to maximize (7) instead, approximating the actual earnings of each individual by the mid-point of the corresponding earnings class interval. The results obtained for the 9th grade and 12th grade samples are presented respectively in the first column of Tables 5 and 6 . In each table there are four parts: the parameter estimates of the decision to continue studying, the parameter estimates of the employment decision, the parameter estimates of the earnings function and the parameters of the covariance matrix. As before asymptotic t-values are presented in parentheses. Note that, for comparison purposes, we also present in the second column of Tables 5 and 6 the OLS estimates of the earnings functions.

Looking at the parameters estimates of the decision to participate in extended education we can see that the results obtained are similar to the ones presented before. See Table 3. As before sex only exerts a significative impact at the 9th grade. Also we find again that age increases the probability to exit school at both educational levels. Moreover for the 12th grade sample the effects of the mother's schooling level and labour market situation on the decision to continue studying are identical to the ones presented in Table 3. For the 9th grade sample the impact of both parents schooling level is of the same type as before, although the values obtained are somewhat different. However, now we do not find a significative impact of the parents' labour market situation variables on the decision to pursue further education.

Turning now to the parameters estimates of the employment decision we see again that the results obtained are similar to the ones obtained previously. See Table 4. Again sex has no significative effect on the probability of getting a job and age only shows a positive and significative impact in the 12th grade sample. The father's level of schooling and labour market situation again have no significative effect on the probability of an individual becoming employed. We also find again that the grade obtained does not influence significantly neither the probability of obtaining a job nor the wage received for the 12th grade sample. However, for the 9 th grade sample the grade obtained affects positively the wage received and also (less significantly) the probability of becoming employed.

In what concerns the parameters of the earnings equation we find again results that are in line with the ones presented in Table 4 . The most important difference concerns the effects of age. Now we do not find any significative effect of age on earnings for the 9th grade sample, and for the 12th grade sample the positive effect found is more pronounced.

Comparing now the maximum likelihood estimates with the OLS results for the earnings equation we see that again, one of the main differences concerns the 


\begin{tabular}{|c|c|c|}
\hline & eq. $(7)$ & OLS \\
\hline Decision function I1 & & \\
\hline const & $-5.794(-13.32)$ & \\
\hline SEX & $-0.441(-4.33)$ & \\
\hline AGE & $0.309(22.83)$ & \\
\hline JOBPA & $-0.202(-1.23)$ & \\
\hline SCPA23 & $-0.310(-2.03)$ & \\
\hline SCPA4 & $-0.401(-1.86)$ & \\
\hline SCPA567 & $-0.920(-1.45)$ & \\
\hline SCMA23 & $-0.296(-2.05)$ & \\
\hline SCMA4 & $-0.733(-2.73)$ & \\
\hline SCMA567 & $-1.187(-1.73)$ & \\
\hline SITPA1 & $-0.203(-1.56)$ & \\
\hline SITPA23 & $-0.061(-0.24)$ & \\
\hline SITMA1 & $0.305(1.24)$ & \\
\hline SITMA2 & $0.521(1.68)$ & \\
\hline SITMA3 & $0.181(0.76)$ & \\
\hline SITMA4 & $0.060(0.20)$ & \\
\hline $\begin{array}{l}\text { Decision function I2 } \\
\text { const }\end{array}$ & $-0.752(-0.58)$ & \\
\hline SEX & $-0.279(-1.49)$ & \\
\hline AGE & $0.047(0.66)$ & \\
\hline SCPA4567 & $0.116(0.42)$ & \\
\hline SITPA4 & $0.610(1.52)$ & \\
\hline GRAD & $0.296(1.30)$ & \\
\hline Earnings function & & \\
\hline const & $3.502(7.73)$ & $3.268(18.65)$ \\
\hline AGE & $0.018(0.97)$ & $0.026(2.71)$ \\
\hline QUAL1 & $0.140(1.46)$ & $0.221(1.98)$ \\
\hline QUAL2 & $0.073(1.24)$ & $0.076(1.37)$ \\
\hline CONT & $0.157(1.83)$ & $0.140(2.16)$ \\
\hline SIZE2 & $0.180(2.32)$ & $0.190(2.51)$ \\
\hline SIZE3 & $0.077(0.77)$ & $0.055(0.68)$ \\
\hline SIZE4 & $0.272(3.10)$ & $0.303(3.23)$ \\
\hline SIZE5 & $0.382(3.77)$ & $0.390(3.79)$ \\
\hline SIZE6 & $0.246(2.29)$ & $0.242(2.89)$ \\
\hline PARTT & $-0.113(-1.61)$ & $-0.122(-1.55)$ \\
\hline GRAD & $0.128(2.01)$ & $0.101(1.86)$ \\
\hline Covariance matrix & & \\
\hline$\sigma_{e}$ & $0.353(4.96)$ & 0.328 \\
\hline$\rho_{e u_{1}}$ & $-0.563(-2.38)$ & \\
\hline$\rho_{e u_{2}}$ & $0.764(4.61)$ & \\
\hline $\mathrm{N}$ & 1978 & 99 \\
\hline $\operatorname{Max}(\log L)$ & -562.47 & \\
\hline
\end{tabular}
Table 5: Maximum likelihood estimates of the general model for the 9th grade 


\begin{tabular}{|l|l|l|}
\hline & eq. (7) & OLS \\
\hline Decision function I1 & $-3.513(-9.40)$ & \\
const & $-0.126(-1.29)$ & \\
SEX & $0.173(15.64)$ & \\
AGE & $-0.174(-1.34)$ & \\
JOBPA & $-0.162(-1.18)$ & \\
SCMA2 & $-0.587(-2.63)$ & \\
SCMA3 & $-0.859(-4.45)$ & \\
SCMA4 & $-1.005(-3.44)$ & \\
SCMA5 & $-1.163(-4.08)$ & \\
SCMA6 & $-1.230(-3.98)$ & \\
SCMA7 & $0.068(0.38)$ & \\
SITMA1 & $0.560(1.89)$ & \\
SITMA2 & $0.214(1.19)$ & \\
SITMA3 & $0.516(2.52)$ & \\
SITMA4 & & \\
\hline Decision function I2 & $-1.632(-3.94)$ & \\
const & $-0.144(-1.05)$ & \\
SEX & $0.095(5.37)$ & \\
AGE & $-0.271(-1.86)$ & \\
SITPA4 & $0.083(0.55)$ & \\
GRAD & & \\
\hline Earnings function & $3.235(16.77)$ & $3.879(39.91)$ \\
const & $-0.190(-4.01)$ & $-0.171(-4.19)$ \\
SEX & $0.030(4.78)$ & $0.013(3.66)$ \\
AGE & $0.052(0.86)$ & $0.015(0.25)$ \\
QUAL1 & $0.099(1.30)$ & $0.108(1.26)$ \\
QUAL2 & $0.136(3.20)$ & $0.126(3.06)$ \\
CONT & $0.079(1.21)$ & $0.077(1.24)$ \\
SIZE2 & $0.139(2.08)$ & $0.148(2.24)$ \\
SIZE3 & $0.213(2.67)$ & $0.187(2.46)$ \\
SIZE4 & $0.277(4.21)$ & $0.271(4.10)$ \\
SIZE5 & $0.370(5.81)$ & $0.367(6.12)$ \\
SIZE6 & $-0.244(-3.94)$ & $-0.230(-3.73)$ \\
PARTT & $0.047(0.92)$ & $0.036(0.84)$ \\
GRAD & & \\
\hline Covariance matrix & $0.386(13.03)$ & 0.385 \\
$\sigma_{e}$ & $0.293(1.68)$ & \\
$\rho_{\text {eu }}$ & $0.794(8.59)$ & \\
$\rho_{\text {eu }}$ & 994 & 279 \\
\hline N & -843.52 & \\
Max (log L) & & \\
\hline & & \\
\hline
\end{tabular}

Table 6: Maximum likelihood estimates of the general model for the 12th grade 
effects of age, as the OLS estimates are closer to the results obtained in Table 4. For the 12th grade sample we also detect some differences on the obtained employer-size premia for SIZE3 and SIZE4. Moreover, for both the 9th and 12th grade samples the wage premium associated with having a permanent labour contract is underpredicted by OLS. The OLS estimates also underpredict the effect of the grade obtained on earnings for 9 th grade sample and the negative effect of sex on wages for the 12th grade sample.

In the bottom parts of Tables 5 and 6 we present information on the variancecovariance structure. Now the results obtained are quite different from the ones presented in Table 4 that were obtained imposing $\rho_{e u_{1}}=0$. We find that the variance of earnings increases slightly with the educational level and again we find, for both educational levels, a positive and now significative correlation between the errors of the wage equation and the errors of the employment decision. However, the correlations obtained are now significantly bigger. This indicates the presence of important selectivity mechanisms. Moreover we also obtain for the 9 th grade an estimate of $\rho_{e u_{1}}$, that is significatively different from zero, and negative which indicates that for the 9 th grade sample the assumption that $\rho_{e u_{1}}=0$ is not a plausible one, as the errors of the earnings equation and the errors of the decision to stop studying are negatively correlated. For the 12 th grade sample, on the contrary, we find a positive but less significantly estimated $\rho_{e u_{1}}$. This means that, while at the 9 th grade level the unobserved factors that increase earnings are negatively correlated with the unobserved factors that increase the probability of choosing to join the labour force, at the 12th grade level these unobserved factors are positively correlated. However, at both educational levels, the unobserved factors that increase earnings are positively correlated with the unobserved factors that increase the probability of obtaining a job.

\subsection{Obtaining predicted earnings}

The estimation results presented in Tables 5 and 6 were used to calculate the predicted earnings for a typical male of each educational level, had he been paid according to each educational level earnings function. Indeed, for each sample the mean levels of the exogenous variables for those individuals that are working are known. ${ }^{2}$ Given these values, predicted log earnings can be calculated using the estimated coefficients of both earnings functions i.e.:

$$
E\left(\bar{W}_{i j}\right)=\alpha_{j}^{\prime} \bar{Z}_{i}
$$

A separate calculation is made of the selectivity effect for those individuals that have actually been paid according to a particular earnings function i.e.:

\footnotetext{
${ }^{2}$ The effect of the dummy variables was also considered in the calculations by giving them their sample proportion values. However, as the dummy qualification variables are not the same for the two educational levels considered we did not include them in the computations.
} 


$$
E\left(\bar{W}_{i i}\right)=\alpha_{i}^{\prime} \bar{Z}_{i}+E\left[e_{i} \backslash I_{1 i}=1 ; I_{2 i}=1\right]
$$

As:

$$
E\left[e \backslash I_{1}=1 ; I_{2}=1\right]=E\left[e \backslash u_{1} \geq-\gamma_{1}^{\prime} X_{1} ; u_{2} \geq-\gamma_{2}^{\prime} X_{2}\right]
$$

and we have that:

$$
f\left(e \backslash u_{1}, u_{2}\right) \sim N\left(\rho_{e u_{1}} \sigma_{e} u_{1+} \rho_{e u_{2}} \sigma_{e} u_{2}, \sigma_{e}^{2}\left(1-\rho_{e u_{1}}^{2}-\rho_{e u_{2}}^{2}\right)\right)
$$

we obtain:

$E\left[e \backslash u_{1} \geq-\gamma_{1}^{\prime} X_{1} ; u_{2} \geq-\gamma_{2}^{\prime} X_{2}\right]=\rho_{e u_{1}} \sigma_{e} E\left(u_{1} \backslash u_{1} \geq-\gamma_{1}^{\prime} X_{1}\right)+\rho_{e u_{2}} \sigma_{e} E\left(u_{2} \backslash u_{2} \geq-\gamma_{2}^{\prime} X_{2}\right)$

so that:

$E\left[e \backslash u_{1} \geq-\gamma_{1}^{\prime} X_{1} ; u_{2} \geq-\gamma_{2}^{\prime} X_{2}\right]=\rho_{e u_{1}} \sigma_{e} \frac{\phi\left(-\gamma_{1}^{\prime} X_{1}\right)}{1-\Phi\left(-\gamma_{1}^{\prime} X_{1}\right)}+\rho_{e u 2} \sigma_{e} \frac{\phi\left(-\gamma_{2}^{\prime} X_{2}\right)}{1-\Phi\left(-\gamma_{2}^{\prime} X_{2}\right)}$.

In Figure 1 predicted log earnings are drawn, excluding the selectivity effect. Some features are worth mentioning. First, no matter what the earnings function used (exit level), the earnings of a typical 12th grade male always exceed those of a typical 9th grade male. Second, predicted earnings differentials between 12th and 9th grade males increase with the exit level. Third, earnings for both type of individuals are always higher at the 9th grade exit level.

[insert Figure 1 here]

In Figure 2 predicted log earnings are drawn, now considering the selectivity effect. As before we have that: (i) for a given earnings function (exit level) the earnings of a typical 12th grade male always exceed those of a typical 9th grade male and (ii) predicted earnings differentials between 12th and 9th grade male individuals increase with the exit level. However now, contrary to what happened before, the earnings profiles by exit level (earnings function) cross, so that individuals that have actually been paid according to a particular earnings function are better paid at that exit level. This result supports the existence of selectivity mechanisms and shows the relevance of comparative advantage considerations in educational choices.

[insert Figure 2 here]

\subsection{Rates of return to education}

Considering the selectivity effect, our estimated results predict a log earnings differential of 0.414 between a typical 12 th grade male individual and a typical 
9th grade male individual. ${ }^{3}$ This result implies an annual rate of return to education somewhat higher than those that are usually obtained for Portugal, and other similar countries, using standard mincerian equations. (See Kiker et al. (1997), Alba-Ramirez and San Segundo (1995)). However, according to our model we can decompose this differential into two effects: a price effect and a quantity effect. Indeed we have that:

$$
W_{12,12}-W_{9,9}=\left(W_{12,12}-W_{12,9}\right)+\left(W_{12,9}-W_{9,9}\right)
$$

where $W_{12,9}$ stands for the hypothetical log earnings that a typical 12th grade male would receive if he had entered employment with a 9th year grade and obtained a typical 12th grade job. Then, the first term in the RHS of the last expression can be seen as a price effect, as it measures the log earnings differential that is due to a different pricing of the same individual and job characteristics, whereas the second term gives us the differential that is associated with different individual and job characteristics for the same set of prices.

Our estimated results give us a price effect of 0.1894 and a quantity effect of 0.2245 . This implies that $54 \%$ of the observed earnings differential is due to different individual characteristics and to differences in the type of jobs available for the two educational levels considered, rather than to a pure pricing effect. Note however that the age difference alone represents $43 \%$ of the quantity effect. This means that, as education does not influence age, if we want a proper measure of the rate of return to education, one should disregard the effect of age on the quantity effect obtained above. So, continuing to assume that education is able to make individuals get different types of jobs, we obtain now a log earnings differential of 0.3174 , which implies an annual rate of return of around 9.6 percent, more in line with the ones obtained for Portugal and other similar countries using standard mincerian equations. However, in these studies the rates of returns to education reported are average rates of return, computed for an average individual, without taking self selection into account, whereas the one we obtain is a marginal one, computed for a typical 12th year grade individual and correcting for selectivity bias and quantity age effects.

Nevertheless, the measure of the returns to education that we presented above was computed from the point of view of a typical 12th grade male graduate. What happens if instead we want to evaluate the gains associated with further education for an individual that reached the 9th grade. The method we employ is similar to the one used by Vella and Gregory (1996) and is the following. We consider a male 23 years old, working full-time, and compute the wage he would receive working with a 9 th grade year certificate, excluding the self selection effect, and assuming that the job he gets is representative of a typ-

\footnotetext{
${ }^{3}$ This value was obtained excluding the level of qualification variables. When we consider these variables the predicted log earnings differential between a typical 12 th grade male and a typical 9 th male is 0.376 . Note that the sample log earnings differential is 0.304 , and that the estimated log earnings differential for all individuals (males and females) is 0.2642.
} 
ical 9th year grade job. ${ }^{4}$ Next we compute the wage the same individual would receive if he had chosen the next education level, i.e. the 12 th grade. To do this we assume, as before, that further education makes him get a representative 12 th grade job and therefore assign this individual the mean values of the firm size and labour contract variables of the new educational level. The obtained log earnings differential is 0.0715 , implying a rate of return to the considered additional investment in education considerably smaller than the one presented before. However, while the former rate of return to education considered selectivity effects the latter does not. This means that self selection explains $78 \%$ of the log earnings differential, suggesting that a proper modelization of self selection mechanisms is indeed important when analysing schooling decisions and measuring the returns to educational choices.

\section{Concluding remarks}

In this paper we analyse educational choices and earnings of individuals at two different levels in the Portuguese educational system. At each potential exit level we consider two decisions: the decision to continue studying and the employment decision, whereas normally only the first decision is modelled. Correlation between the error terms of the earnings functions and the decision functions, for each level of education, is allowed and we correct for the potential selectivity bias.

We find empirical support for the existence of selectivity bias as the errors of the earnings functions are correlated with the disturbances of both decision functions for both educational levels considered. Moreover it is precisely the existence of selectivity mechanisms that renders the decisions actually taken by individuals optimal in terms of comparative earnings advantage.

The obtained marginal rates of return to additional education vary between 2.3 and 9.6 percent per additional year of schooling, depending on whether or not selectivity effects are excluded from the computations. This finding reinforces again the importance of selectivity mechanisms in explaining educational choices.

\section{References}

[1] Alba-Ramirez, A. and M. J. San Segundo, (1995), "The Returns to Education in Spain", Economics of Education Review, 14, no 2, 155-166.

[2] Brown, C. and J. Medoff, (1989), "The Employer Size-Wage Effect", Journal of Political Economy, 97, no.5, 1027-1059.

\footnotetext{
${ }^{4}$ This means that we assign this individual with the mean values of the firm size and labour contract variables.
} 
[3] Co, C., I. Gang and M. Yun, (2000),"Returns to Returning", Journal of Population Economics, 13, 57-79.

[4] Fishe, R., R. Trost and M. Lurie, (1981), "Labor Force Earnings and College Choice of Young Women: An Examination of Selectivity Bias and Comparative Advantage", Economics of Education Review, 1, 169-191.

[5] Garen, J., (1984), "The Returns to Schooling: A Selectivity Bias Approach with a Continuous Choice Variable", Econometrica, 52, no.5, 1199-1218.

[6] Hartog, J., G. Pfann and G. Ridder, (1989), "(Non)-Graduation and the Earnings Function: An Inquiry on Self-Selection", European Economic Review, 33, no. 7, 1373-1395.

[7] Heckman, J., (1979), "Sample Selection Bias as a Specification Error", Econometrica, 47, 153-161.

[8] Kiker, B. F., M. C. Santos and M. Mendes de Oliveira, (1997), "Overeducation and Undereducation: Evidence for Portugal", Economics of Education Review, 16, no 2, 111-125.

[9] Trost, R. P. and L.-F. Lee, (1984), "Technical Training and Earnings: A Polychotomous Choice Model with Selectivity", Review of Economics and Statistics, 66, 151-156.

[10] Tunali, I., (1986), "A General Structure for Models of Double-Selection and an Application to a Joint Migration/Earnings Process with Remigration", Research in Labour Economics, 8(B), 235-283.

[11] Vella, F. and R. G. Gregory, (1996), "Selection Bias and Human Capital Investment: Estimating the Rates of Return to Education for Young Males", Labour Economics, 3, 197-219.

[12] Willis, R. J. and S. Rosen, (1979), "Education and Self-Selection", Journal of Political Economy, 87, no. 5b, 507-536. 
Figure 1 - Predicted earnings excluding the selectivity effect

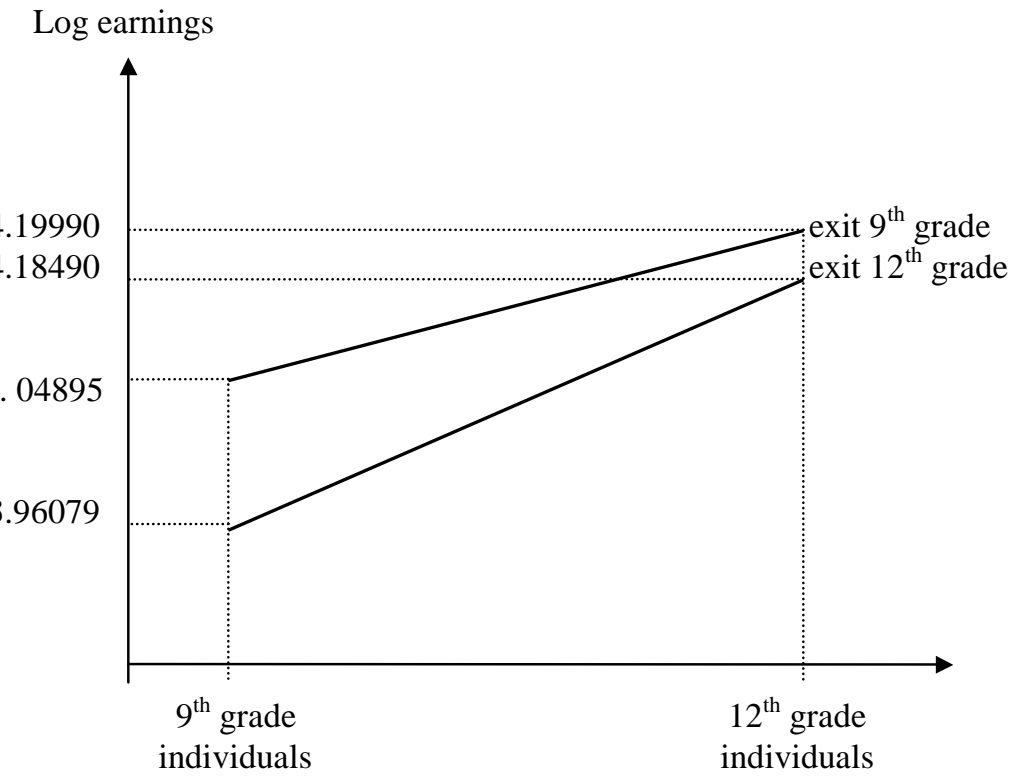

Figure 2 - Predicted earnings including the selectivity effect

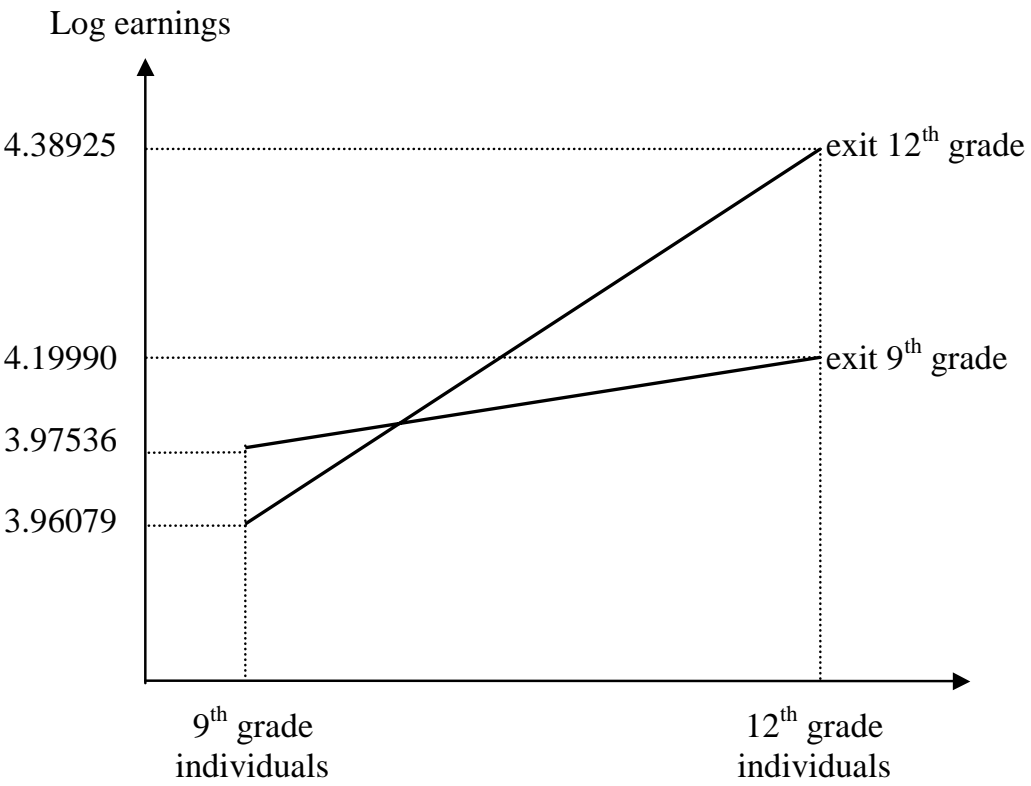




\section{IZA Discussion Papers}

No Author(s)

141 R. Hujer M. Wellner

142 J. J. Dolado

F. Felgueroso

J. F. Jimeno

143 P. J. Luke

M. E. Schaffer

144 G. Saint-Paul

145 M.-S. Yun

146 T. K. Bauer

J. P. Haisken-DeNew

147 M. Belot

J. C. van Ours

148 L. Goerke

149 R. Lalive

J. C. van Ours

J. Zweimüller

150 J. DiNardo

K. F. Hallock

J.-St. Pischke

151 M. Ward

152 J. J. Dolado

F. Felgueroso

J. F. Jimeno

153 A. S. Kalwij

M. Gregory

154 M. Gerfin

M. Lechner

155 J. Hansen
Titel

Area

Date

The Effects of Public Sector Sponsored Training on Individual Employment Performance in East Germany

Explaining Youth Labor Market Problems in Spain: 3 Crowding-Out, Institutions, or Technology Shifts?

Wage Determination in Russia: An Econometric 4 Investigation

$4 / 00$

Flexibility vs. Rigidity: Does Spain have the worst of 1 both Worlds?

Decomposition Analysis for a Binary Choice Model 7

$4 / 00$

Employer Learning and the Returns to Schooling 5

$4 / 00$

$4 / 00$

Does the Recent Success of Some OECD 3

3

Countries in Lowering their Unemployment Rates

Lie in the Clever Design of their Labour Market

Reforms?

Employment Effects of Labour Taxation in an Efficiency Wage Model with Alternative Budget Constraints and Time Horizons

The Impact of Active Labor Market Programs and Benefit Entitlement Rules on the Duration of Unemployment

Unions and the Labor Market for Managers

Gender, Salary and Promotion in the Academic 5 Profession

$5 / 00$

The Role of the Minimum Wage in the Welfare 3 State: An Appraisal

$5 / 00$

Overtime Hours in Great Britain over the Period 3 1975-1999: A Panel Data Analysis

Microeconometric Evaluation of the Active Labour 6 Market Policy in Switzerland

$5 / 00$

$5 / 00$

The Duration of Immigrants' Unemployment Spells: $\quad 1 / 3$ Evidence from Sweden 


\begin{tabular}{|c|c|c|c|c|}
\hline 156 & $\begin{array}{l}\text { C. Dustmann } \\
\text { F. Fabbri }\end{array}$ & $\begin{array}{l}\text { Language Proficiency and Labour Market Per- } \\
\text { formance of Immigrants in the UK }\end{array}$ & 1 & $5 / 00$ \\
\hline 157 & $\begin{array}{l}\text { P. Apps } \\
\text { R. Rees }\end{array}$ & $\begin{array}{l}\text { Household Production, Full Consumption and } \\
\text { the Costs of Children }\end{array}$ & 7 & $5 / 00$ \\
\hline 158 & $\begin{array}{l}\text { A. Björklund } \\
\text { T. Eriksson } \\
\text { M. Jäntti } \\
\text { O. Raaum } \\
\text { E. Österbacka }\end{array}$ & $\begin{array}{l}\text { Brother Correlations in Earnings in Denmark, } \\
\text { Finland, Norway and Sweden Compared to the } \\
\text { United States }\end{array}$ & 5 & $5 / 00$ \\
\hline 159 & $\begin{array}{l}\text { P.- J. Jost } \\
\text { M. Kräkel }\end{array}$ & Preemptive Behavior in Sequential Tournaments & 5 & $5 / 00$ \\
\hline 160 & M. Lofstrom & $\begin{array}{l}\text { A Comparison of the Human Capital and Signaling } \\
\text { Models: The Case of the Self-Employed and the } \\
\text { Increase in the Schooling Premium in the 1980's }\end{array}$ & 5 & $6 / 00$ \\
\hline 161 & $\begin{array}{l}\text { V. Gimpelson } \\
\text { D. Treisman } \\
\text { G. Monusova }\end{array}$ & $\begin{array}{l}\text { Public Employment and Redistributive Politics: } \\
\text { Evidence from Russia's Regions }\end{array}$ & 4 & $6 / 00$ \\
\hline 162 & $\begin{array}{l}\text { C. Dustmann } \\
\text { M. E. Rochina- } \\
\text { Barrachina }\end{array}$ & $\begin{array}{l}\text { Selection Correction in Panel Data Models: An } \\
\text { Application to Labour Supply and Wages }\end{array}$ & 6 & $6 / 00$ \\
\hline 163 & $\begin{array}{l}\text { R. A. Hart } \\
\text { Y. Ma }\end{array}$ & Why do Firms Pay an Overtime Premium? & 5 & $6 / 00$ \\
\hline 164 & $\begin{array}{l}\text { M. A. Shields } \\
\text { S. Wheatley Price }\end{array}$ & $\begin{array}{l}\text { Racial Harassment, Job Satisfaction and Intentions } \\
\text { to Quit: Evidence from the British Nursing } \\
\text { Profession }\end{array}$ & 5 & $6 / 00$ \\
\hline 165 & P. J. Pedersen & $\begin{array}{l}\text { Immigration in a High Unemployment Economy: } \\
\text { The Recent Danish Experience }\end{array}$ & 1 & $6 / 00$ \\
\hline 166 & $\begin{array}{l}\text { Z. MacDonald } \\
\text { M. A. Shields }\end{array}$ & $\begin{array}{l}\text { The Impact of Alcohol Consumption on Occupa- } \\
\text { tional Attainment in England }\end{array}$ & 5 & $6 / 00$ \\
\hline 167 & $\begin{array}{l}\text { A. Barrett } \\
\text { J. FitzGerald } \\
\text { B. Nolan }\end{array}$ & $\begin{array}{l}\text { Earnings Inequality, Returns to Education and } \\
\text { Immigration into Ireland }\end{array}$ & 5 & $6 / 00$ \\
\hline 168 & $\begin{array}{l}\text { G. S. Epstein } \\
\text { A. L. Hillman }\end{array}$ & $\begin{array}{l}\text { Social Harmony at the Boundaries of the Welfare } \\
\text { State: Immigrants and Social Transfers }\end{array}$ & 3 & $6 / 00$ \\
\hline 169 & R. Winkelmann & $\begin{array}{l}\text { Immigration Policies and their Impact: The Case of } \\
\text { New Zealand and Australia }\end{array}$ & 1 & $7 / 00$ \\
\hline 170 & $\begin{array}{l}\text { T. K. Bauer } \\
\text { K. F. Zimmermann }\end{array}$ & $\begin{array}{l}\text { Immigration Policy in Integrated National } \\
\text { Economies }\end{array}$ & 1 & $7 / 00$ \\
\hline 171 & $\begin{array}{l}\text { C. Dustmann } \\
\text { F. Windmeijer }\end{array}$ & $\begin{array}{l}\text { Wages and the Demand for Health - A Life Cycle } \\
\text { Analysis }\end{array}$ & 5 & $7 / 00$ \\
\hline 172 & D. Card & $\begin{array}{l}\text { Reforming the Financial Incentives of the Welfare } \\
\text { System }\end{array}$ & 3 & $7 / 00$ \\
\hline 173 & D. S. Hamermesh & Timing, Togetherness and Time Windfalls & 5 & $7 / 00$ \\
\hline
\end{tabular}



M. Ward

180 T. K. Bauer I. N. Gang

E. Wasmer

Y. Zenou

184 M. Corak

B. Gustafsson

T. Österberg

185 H. Bonin

K. F. Zimmermann

A. S. Kalwij

A. Zaidi 
223 M. Rosholm

Wages, Training, and Job Turnover in a Searchformer Soviet Union to Israel: Who is coming when?

228 G. Brunello

The College Wage Gap in 10 European

S. Comi Countries: Evidence from Two Cohorts and Earnings: An Empirical Study for Portugal 